\title{
Maurice Dommanget
}

1928

\section{"L'enfance sous}

la Commune"

Un document produit en version numérique par Stéphane Julien, bénévole, Courriel: stephane.julien@snuipp.fr

Dans le cadre de la collection: "Les classiques des sciences sociales" Site web: http://classiques.uqac.ca/

Une collection développée en collaboration avec la Bibliothèque Paul-Émile-Boulet de l'Université du Québec à Chicoutimi Site web: http://bibliotheque.uqac.ca/ 
Cette édition électronique a été réalisée par Stéphane Julien, bénévole, Courriel: stephane.julien@snuipp.fr

à partir de :

Maurice Dommanget

"L'enfance sous la Commune"

Une édition électronique réalisée à partir de l'article paru dans la revue Les Cahiers du bolchevisme, ${ }^{\circ}$ du 15 avril 1928, pp. 212-216. Saisie du texte par Stéphane Julien.

Polices de caractères utilisée :

Pour le texte: Times New Roman, 14 points.

Pour les citations : Times New Roman, 12 points.

Pour les notes de bas de page : Times New Roman, 12 points.

Édition électronique réalisée avec le traitement de textes Microsoft Word 2004 pour Macintosh.

Mise en page sur papier format : LETTRE (US letter), 8.5” x 11")

Édition complétée le 2 décembre 2006 à Chicoutimi, Ville de Saguenay, Québec. 


\section{"L'enfance sous la Commune"}

"Si l'on admet que la profondeur d'une Révolution se mesure à l'ardeur des femmes et des enfants, il faut en conclure, étant donné la large participation des enfants et de leurs mères, que la Commune constitue la plus forte tempête révolutionnaire qui ait soufflé sur la capitale."

On ne saurait séparer artificiellement les efforts de la Commune en vue d'instruire l'enfance de ses tentatives touchant les orphelinats et l'utilisation militaire de la jeunesse.

Il faut distinguer ici l'enfance ouvrière de l'enfance bourgeoise.

Les enfants des quartiers riches du centre qui, pendant le siège, avaient toujours été privilégiés par rapport aux enfants des quartiers ouvriers de la périphérie, continuèrent à bénéficier de la situation sociale de leurs parents. Comme par le passé, ils purent même fréquenter le Guignol jusqu'au jour où les bombes versaillaises, dépassant le rond-point des Champs-Elysées, vinrent tomber devant le cirque. Alors, comme le nota spirituellement un chroniqueur de l'époque, "Polichinelle, le commissaire et le diable" furent contraints de déménager. 
Dans les quartiers ouvriers, pendant que les parents combattaient ou travaillaient, un grand nombre de jeunes apprentis licenciés et d'enfants qui ne fréquentaient pas l'école, livrés à eux-mêmes, traînaient dans les rues. On se demande même comment vivaient ceux qui, ayant quitté la maison paternelle, vagabondaient sur le pavé de la capitale. Il est certain que les dures conditions dans lesquelles se trouvait placée la classe ouvrière n'étaient pas sans influencer douloureusement sur toute l'enfance prolétarienne. Toutefois, insouciants, comme on l'est à cet âge, gamins et gamines jouaient en plein bombardement. Et quand un obus tombait non loin d'eux, on les voyait parfois se précipiter sur les éclats qu'ils emportaient glorieusement.

Une statistique dressée par Allix nous apprend que dans le VIII $^{\mathrm{e}}$ arrondissement, sur 6.251 garçons et filles de 7 à 15 ans, les écoles communales ne recevaient que 3.030 élèves, même pas la moitié. Encore est-il bon de noter qu'Allix a compté parmi les 3.030 élèves tous les enfants de 3 à 7 ans fréquentant les asiles de l'arrondissement. En tenant compte de ce fait et en n'oubliant pas que l'âge scolaire commence à 5 ans et non à 7 , on arrive à cette conclusion qu'au moins 4.000 enfants d'âge scolaire, dans un arrondissement comme le VIII ${ }^{e}$, où l'on s'occupait beaucoup des écoles, restaient en dehors des établissements d'instruction. Il est clair que les mesures prises par plusieurs municipalités contre la mauvaise fréquentation scolaire ne pouvaient constituer qu'un faible palliatif sans distribution de galoches et de vêtements, sans l'institution de cantines, mesures réclamées par la détresse économique des travailleurs.

Du côté des salles d'asiles publics, un effort fut fait. Le personnel qui avait toujours été au-dessous des besoins s'augmenta à la suite de plusieurs appels. Dans le VIIIe arrondissement cité plus haut, on comptait 271 enfants de 3 à 7 ans dans deux salles d'asile.

Nous avons déjà eu l'occasion de signaler la fondation d'orphelinats sous l'égide des municipalités. On doit, semble-t-il, à l'initiative privée la création de l'orphelinat de la Garde Nationale, boulevard Victor-Hugo, 40 (ancien boulevard Hauss- 
mann), dans un local aéré et sain contenant 300 lits. Les enfants, garçons et filles, y étaient admis tous les jours, de 1 à 4 heures, sur la présentation d'un certificat "non motivé" du sergent-major constatant que le père appartient à une compagnie de la garde nationale.

Le docteur Raymond, désireux de secourir l'enfance malheureuse, faisait appel, d'une part, à toutes les mères de famille ayant des vêtements, chemises ou souliers d'enfants, sans usage, et, d'autre part, à "toute les citoyennes de cœur" qui voudraient lui apporter leur concours pour "soigner et instruire" les garçons et filles confiés à ses soins.

Bien que ce soit peut-être empiéter sur la partie militaire de l'histoire de la Commune, il convient, à cette place, de mettre en relief la belle conduite de tous ces braves petits prolétaires qui, surexcités par la situation révolutionnaire, aigris par les privations successives, devaient, comme le reconnaîtront plus tard les juges des conseils de guerre, "fournir à l'insurrection un concours très utile" 1 .

C'est un fait que le gamin de paris, ce gavroche si prompt aux polisonneries autant qu'à l'héroïsme, a joué un rôle à toutes les époques de crise révolutionnaire.

On ne vit pas seulement des bandes d'enfants ouvriers promener dans les rues de petits drapeaux rouges au chant de la Marseillaise et aux cris de: Vive la Commune ! par milliers, des enfants se précipitèrent au combat des avant-postes ou firent le coup de feu sur les barricades. "Ils suivaient les bataillons aux tranchées, dans les forts, s'accrochaient aux canons", a noté Lissagaray.

Les journaux du temps ${ }^{2}$ relatent leurs traits de courage.

1 Les procès de la Commune, $21^{\mathrm{e}}$ livraison (Compte rendu du procès des Pupilles de la Commune.

2 La Commune, le Mot d'ordre, l'Officiel 
Cueillons-en quelques-uns:

V. Thiebaut, quatorze ans, accourait à travers les balles pour donner à boire aux défenseurs du rond-point de Saint-Ouen. Les obus ayant forcé les fédérés à se replier,, ceux-ci allaient sacrifier une pièce de vin appartenant à leur bataillon. Mais l'enfant la défonça au péril de sa vie en s'écriant: "Ils ne boiront toujours pas notre vin." Puis il saisit une carabine, la chargea et tua un officier de gendarmerie, après quoi il sauva un fourgon du bataillon.

Charles Benderitter, quinze ans, s'offrit comme artilleur à la $7^{\circ}$ batterie de la Marseillaise. Son enthousiasme, sa gaieté lui attirèrent l'affection de ses camarades; la sûreté de son coup d'œil le fit remarquer. Pendant dix jours et dix nuits, il ne quitta pas sa pièce et chacun s'assurait de l'exactitude de son tir, un éclat d'obus l'atteignit à la jambe et lui coupa presque le pied. Il tomba en s'écriant: "Vive la République!". Transporté à l'ambulance, il supporta vaillamment ses souffrances. Voilà un autre Bara que la bourgeoisie française se gardera bien de donner en exemple aux petits prolétaires dans ses manuels d'histoire.

Les "Tirailleurs Painchaud", qui comprenaient des enfants de 15 ans, se livrèrent à des coups d'audace. On les vit, le 16 mai, risquer une escapade des plus hardies. Sans ordre et en cachette, ils descendirent des remparts à l'aide d'échelles et s'aventurèrent dans le bois de Boulogne. Au bout d'une heure, ils rentrèrent rapportant des chassepots enlevés à des gendarmes qu'ils avaient surpris. Dans les mêmes parages de la porte Maillot, Eugène Vaxivière, treize ans et demi, blessé plus d'un mois auparavant, avait continué de servir malgré sa blessure.

Le 23 mai, quand le Comité de Salut Public annonça que l'ennemi s'était introduit dans la capitale et lança son appel célèbre: "Tout le monde aux barricades!", il trouva un puissant écho parmi l'enfance ouvrière. 
Benoît Malon estime à 5000 le nombre des enfants qui, aux sombres jours de la Semaine sanglante, combattirent ou moururent sur les barricades aux cris de: Vive la Commune, Vive la république universelle, Vive le Travail! Cette estimation paraît fortement exagérée à première vue. Mais quand on sait que sur les 20.000 fédérés morts il y eut bien des enfants, quand on relève 651 enfants arrêtés officiellement, quand on voit bon nombre condamnés à la déportation, à l'emprisonnement ou affectés dans les maisons de correction par lres conseils de guerre, on se dit que benoît Malon n'a peut-être pas tellement forcé la note.

Tout un corps de jeunes combattants fut habillé, équipé et armé les 21 et 22 mai. On l'appela le corps des "Pupilles ou Enfants de la Commune". Il était caserné place du Château-d'Eau, actuellement place de la République. Ce corps comprenait une centaine de garçons de 10 à 16 ans, qui "s'étaient enrôlés de leur plein gré et recevaient une solde de quinze sous par jour". C'étaient des fils d'ouvriers, pour la plupart chétifs. Ils participèrent à la construction et assurèrent la défense des barricades établies aux abords de la place du Château-d'Eau et dans la rue du Faubourg-du-Temple. Les deux barricades de la rue de l'Entrepôt paraissent avoir été entièrement défendues par eux. Maison par maison, tirant jusqu'à cinquante coups de feu, ils défendirent la rue Magnan pour se replier sur la grande barricade du Château-d'Eau, qui obstruait l'entrée du boulevard Voltaire. Là, ils multiplièrent les actes de bravoure et de témérité. L'un d'eux saisit un guidon et monta sur les pavé, narguant l'ennemi, lui reprochant d'avoir tué son père. Vermorel, Jaclard, Theiz, Lisbonne dirent à l'enfant de descendre. Il refusa, s'obstinant jusqu'au moment où une balle versaillaise le foudroya. Un peu plus tard, au même endroit, le vieux Delescluze ne devait pas mourir autrement que ce jeune héros. On vit, là encore, un gamin de quinze ans, Dauteuille, franchir les pavés et, sous une grêle de balles, ramener aux fédérés le képi d'un lieutenant tué en avant de la barricade.

Le plus enragé tireur d'une des barricades du faubourg du Temple fut un enfant dont le tranquille héroïsme est passé à la postérité. La barricade enlevée, tous ses défenseurs sont alignés 
le long d'un mur pour être fusillés. Alors l'enfant demande à l'officier versaillais quelques minutes de répit, le temps d'aller chez lui, tout près, porter sa montre d'argent et dire adieu à sa mère. L'officier le laisse partir:

"... - Va-t'en, drôle ! - L'enfant s'en va. -- Piège grossier !

Et les soldats riaient avec leur officier,

Et les mourants mêlaient à ce rire leur râle;

Mais ce rire cessa, car soudain l'enfant, pâle,

Brusquement reparut, fier comme Viala,

Vint s'adosser au mur et leur dit: "Me voilà !"

La mort stupide eut honte et l'officier fit grâce." 3 .

Hélas ! pour un jeune héros épargné, combien de centaines de petits prolétaires, "de graine d'insurgés", - comme disaient les bourreaux galonnés, - furent sacrifiés à la vengeance bourgeoise. A défaut des faits qui viennent d'être cités, l'étendue, la cruauté de cette répression attesteraient, s'il en était besoin, la part importante prise par l'enfance ouvrière à la défense de la Commune.

Maurice Dommanget

(Extrait de l'Instruction publique sous la Commune, Édition de l'Internationale de l'Enseignement)

3 Victor Hugo, L'Année terrible. 